\title{
Public Transportation Hub Location with Stochastic Demand: An Improved Approach Based on Multiple Attribute Group Decision-Making
}

\author{
Sen Liu, Zhilan Song, and Shuqi Zhong \\ School of Logistics, Yunnan University of Finance and Economics, Kunming 650221, China \\ Correspondence should be addressed to Sen Liu; liusencool@gmail.com
}

Received 8 October 2015; Accepted 24 November 2015

Academic Editor: Gabriella Bretti

Copyright (c) 2015 Sen Liu et al. This is an open access article distributed under the Creative Commons Attribution License, which permits unrestricted use, distribution, and reproduction in any medium, provided the original work is properly cited.

\begin{abstract}
Urban public transportation hubs are the key nodes of the public transportation system. The location of such hubs is a combinatorial problem. Many factors can affect the decision-making of location, including both quantitative and qualitative factors; however, most current research focuses solely on either the quantitative or the qualitative factors. Little has been done to combine these two approaches. To fulfill this gap in the research, this paper proposes a novel approach to the public transportation hub location problem, which takes both quantitative and qualitative factors into account. In this paper, an improved multiple attribute group decision-making (MAGDM) method based on TOPSIS (Technique for Order Preference by Similarity to Ideal Solution) and deviation is proposed to convert the qualitative factors of each hub into quantitative evaluation values. A location model with stochastic passenger flows is then established based on the above evaluation values. Finally, stochastic programming theory is applied to solve the model and to determine the location result. A numerical study shows that this approach is applicable and effective.
\end{abstract}

\section{Introduction}

With the development of economy and the expansion of city, the role of the public transportation system has become increasingly important. The location and planning of public transportation hubs is an important step to improving transportation efficiency, optimizing resources allocation, and reducing energy consumption $[1,2]$.

The hub location problems (HLPs) involve locating consolidating facilities when flow (travelers, airline passengers, telecom messages, cargo, farm products, mail, etc.) must be sent from origin to destination nodes (e.g., cities). Trips between origin-destination (OD) nodes may represent direct links between OD pairs or indirect paths passing through a hub [1]. Researchers have used various methods in an attempt to solve the hub location problem [3-5]. These methods can be categorized into different subject areas like single-HLP, pHLP, multiple allocation p-HLP, p-HLP with fixed link cost, minimum-value flow on links model, p-HLP with limited capacity, continuous $\mathrm{p}$-HLP, multiobjective $\mathrm{p}$-HLP, $\mathrm{p}$-Hub center location problem, p-Hub covering location problem, and hub set covering location problem [6,7].

However, current studies have some limitations; the existing researches on transportation hub location usually focus only on either the quantitative (e.g., cost, speed) or qualitative aspects (e.g., commercial potential). With regard to the quantitative factors, scholars usually apply p-HLP, gravity method, nonlinear programming and stochastic programming, and so forth to obtain optimal solutions $[1,2,5,8]$, However, such models cannot incorporate all factors, especially those factors that cannot be measured precisely. While MAGDM, fuzzy evaluation methods [9-13] can make the qualitative factors quantified, the comparability of the quantitative elements is weakened in such methods. Neglecting the influence of quantitative or qualitative factors will eventually affect the rationality of the hub location result.

We suggest that the public transportation hub location problem should consider both quantitative and qualitative factors simultaneously given that they directly influence the optimal location result. Therefore, in order to solve the above 
problem, this paper proposes a novel line of thought that considers both quantitative and qualitative factors in the public transportation hub location problem. More specifically, we combine an improved multiple attribute group decisionmaking (MAGDM) method, which converts the qualitative factors into quantitative values, with the stochastic location model.

Our study contributes to extant research in three ways. First, unlike previous research that focuses solely on either quantitative or qualitative factors, our model takes both factors into account. Quantitative and qualitative factors should be considered simultaneously in the model because both have influential impacts on the location of public transportation hubs. Second, we propose an improved MAGDM that can objectively weight attributes and DMs (decisionmakers) simultaneously. That is, the decision-making process is conducted under the condition that the attributes and DMs weights are unknown in advance. Weighting attributes and DMs objectively can reduce the subjective elements in the decision-making process. Finally, unlike most of the existing research on public transportation hub location that assumes that passenger flow is known, we treat passenger flow as a stochastic variable in the model. Our method is more practical. Because passenger flow is influenced by many factors that are difficult to estimate and predict, the stochastic programming in our approach should lead to more reasonable implications, compared with research that assumes passenger flow is known.

The rest of the paper is structured as follows. Section 2 reviews related literature. Section 3 introduces the stochastic transportation location model. In Section 4, an improved MAGDM method with unknown attributes and DM weights is presented and discussed. Section 5 provides the general steps of the proposed method; and Section 6 demonstrates a numerical example. Finally, Section 7 presents our conclusions.

\section{Literature Review}

The goal of transportation hub location is to choose hubs in a set of alternatives to minimize costs or maximize benefits. In essence, the transportation hub location problem is one of several types of hub location problems. Many researchers have in fact studied hub location problems $[1,3,4,14$, 15]. Most of them address the p-hub median problem and its variants. As an extension of the hub location problem, Campbell et al. $[8,16]$ propose a new hub location approach called the hub arc location model, and they analyze the characteristics of the optimal solution with special attention to spatial patterns and relationships. The authors provide integer programming formulations and optimal algorithms for these hub arc problems. With this method, one can not only locate discrete hub facilities but also reduce the unit flow cost.

Robinson and Bookbinder [17] propose a mixed integer programming model to solve the location problem of finishing plants and distribution centers between Canada, Mexico, and the United States; then, through a real-world example, overall supply chain costs (total system costs of inventory, transportation, and facilities) can be minimized under those circumstances of North American Free Trade Agreement (NAFTA). Alumur and Kara [18] review over 100 papers regarding the network hub location problem, including the p-hub median problem, the hub location problem with fixed costs, the p-hub center problem, and the hub covering problem. Based on these papers, the authors analyze the trends and provide a synthesis of the literature.

In order to make models that in a closer way reflect the real world, some scholars have studied the hub location problem with stochastic variables. Contreras et al. [19] study the hub location problem in which demands or transportation costs are stochastic, and they prove that stochastic problems with uncertain demands or dependent transportation costs are equivalent to a deterministic expected value problem (EVP). The authors propose a Monte-Carlo simulationbased algorithm, combined with a Benders decomposition algorithm, to solve the model. Louveaux and Peeters [20] study how to convert the uncapacitated facility location problem into a dual stage stochastic problem. The authors propose a solution to the dual-based procedure. Ball and Lin [21] study the emergency services facilities point location problem from the perspective of system reliability. They convert the stochastic problem of the model into a $0-1$ integer programming problem and solve it by the branchand-bound method. Albareda-Sambola et al. [22] convert the stochastic facility location and routing problem into a bilevel programming problem and propose a two-phase heuristics solution. Zhou and Liu [23] propose a hybrid intelligence algorithm which combines the stochastic simulation and genetic algorithm. This new algorithm can effectively solve the chance-constrained model and expected value model of facility location and distribution problem under the circumstances of stochastic demands. Gelareh and Pisinger [24] propose a novel mathematical model to solve the hub location problem of liner shipping companies. They assume the demand is elastic and then propose a mixed integer linear programming formulation for the simultaneous design of network and fleet deployment.

Expanding the current research on facility location that only considers the demands as either stochastic or fuzzy, Wen and Kang [25] view the demands as being stochastic and fuzzy simultaneously. The authors propose the expected cost minimization model, $(\alpha, \beta)$-cost minimization model, and chance maximization model and develop a hybrid genetic algorithm to solve these models. Gabor and Van Ommeren [26] propose a 2-approximation algorithm to solve the facility location problem when the demands and inventory are stochastic. The numerical example proves that their method can effectively obtain a near optimal solution. Wang and He [27] propose a robust optimization model using the formation of regret model on the basis of the stochastic optimization model and provide an enumeration method and genetic algorithm to solve the model. The numerical example demonstrates that their method is better than the stochastic optimization model. Yang et al. [28, 29] propose a method which combines the multiobjective fuzzy optimization model with a genetic algorithm to solve the fire station location problem. The model fully incorporates the fuzzy nature of decision-makers 
and the different fire demands of the different regions. In their model, the authors consider that construction costs, circulation costs, and customer demands are all fuzzy variables. The authors propose a logistics distribution center location model under such a fuzzy environment, establish a fuzzy chanceconstrained model, and combine the Tabu search algorithm with the genetic algorithm to solve the model.

Introducing stochastic variables into the location model renders the decision results more accurate. However, there are still several influential factors, such as policy environments, hydrological conditions, and commercial potential, that cannot be defined as a variable, or a stochastic variable. Therefore, the location model with stochastic programming still does not take many factors into account. Furthermore, many factors cannot be quantified. On the other hand, modeling real-life situations will introduce many quantitative and qualitative factors, and the models will become more complicated [30]. In order to improve the quality of location decision, we should combine both qualitative and quantitative factors in a model.

Expert assessment methods are the most widely used methods to measure qualitative factors. Among them, the group decision-making method (GDM) is one of the most effective and efficient ways. In order to make decision results more accurate, researchers began to use fuzzy set theory to study MAGDM problems. As an important component of MAGDM, fuzzy multiattribute group decision-making (FMAGDM) is a difficult and hot research area [11, 31].

Herrera et al. [32-34] have conducted a number of studies on multiattribute group decision-making problems based on language preference relationship. They use fuzzy sets to represent language variables and convert the variables into triangular or trapezoidal fuzzy numbers. Herrera et al. [32] and Herrera and Martínez [35] propose a method called linguistic 2-tuple representation model to represent the language variables based on the above fuzzy model.

Karacapilidis [36] find that the decision-makers may establish a common belief in the decision process by following a series of well-defined communicative actions. Then, they defined these actions and take them into consideration in the group decision process, which make the decision results more reliable. Lahdelma and Salminen [37] propose a stochastic multiattribute method which effectively provides decision-making support for decision-makers in a group decision. The paper proposes a SMAA (Stochastic Multicriteria Acceptability Analysis), an approach which can obtain a better compromise solution compared with that of traditional methods. Fenton and Wang [38] use linguistic variables and triangular fuzzy numbers to describe the opinions and attitudes of decision-makers and propose a fuzzy group decision-making approach based on risk and credible analysis. The numerical example shows that their method can effectively solve the inaccuracy and subjectivity problem in the decision-making system. Hochbaum and Levin [39] improve the existing methods of group decisionmaking. They present a new paradigm using an optimization framework that provides a specific performance measure for the quality of the aggregate ranking as per its deviations from the individual decision-makers' rankings. The new model is based on rankings provided with intensity; that is, the degree of preference is quantified. The model allows for flexibility in decision protocols and can take into consideration imprecise beliefs, less than full confidence in some of the rankings, and differentiating between the expertise of the reviewers. This method is simpler and more efficient than other existing methods and can be effectively applied in large-scale multiattribute decision-making problems.

The above studies optimize and improve the MAGDM method through different ways. Most of them assume that the attribute weights or DM weights are already known. However, because every project has its own specific influential factors and experts from different fields have their individual specific background knowledge, skills, and experience, subjective assignment of values to attribute weights and DM weights will increase the uncertainty of the decision-making process.

For the determination of experts' weights, French Jr. [40] measures the decision-makers' relative importance through the influence degree among the DMs. Bodily [41] establishes another decision-making team to give weights to the initial decision members and work out the weights of the initial decision members by measuring the additional preference value deviation. Yue et al. [42] decide the weights of attributes by converting attribute values into intuitive fuzzy numbers. Parreiras et al. [43] propose a flexible consensus scheme to establish the orders. Yue $[44,45]$ proposes a calibration value method to calculate weights. Xu [46] improves Bodily's method and proposes a more direct method to calculate weights. Mirkin and Fishburn [47] give two eigenvector methods to measure the relative importance of decisionmakers. Van den Honert [48] uses the REMBRANDT (ratio estimation in magnitudes of deci-bells to rate alternatives which are nondominated) method, which is the combination of AHP and SMART (the sample multiattribute rating technique) to quantify the decision-makers' ability. Ramanathan and Ganesh [49] present a simple method which uses decision-makers' own subjective opinions to calculate the decision-makers' weights.

For the determination of attribute weights, currently most studies focus on the aggregation operator. Herrera et al. $[33,34]$ propose a linguistic ordered weighted averaging operator. $\mathrm{Xu}$ [50-54] develops an LWGA (Linguistic Weighted Geometric Averaging) operator, an LOWGA (Linguistic Ordered Weighted Geometric Averaging) operator, and a ULHA (Uncertain Linguistic Hybrid Aggregation) averaging operator. Merigó et al. [55] propose a belief structure-linguistic ordered weighted averaging (BS-LOWA) and the BS-linguistic hybrid averaging (BS-LHA) based on Dempster-Shafer theory of evidence. Meng and Tang [56] develop some new 2-tuple linguistic hybrid aggregation operators, which are called the extended 2-tuple linguistic hybrid arithmetical weighted (ET-LHAW) operator and the extended 2-tuple linguistic hybrid geometric mean (ETLHGM) operator; Xu et al. [57] develop the ULPA operator (uncertain linguistic operators under uncertain linguistic environments) and the ULPOWA operator (uncertain linguistic weighted operator).

As shown above, current studies usually obtain attribute weights and experts' weights in one of three ways: (1) both 
attribute weights and experts' weights are assumed to be known; (2) attribute weights are assumed to be known, but experts' weights are calculated; (3) experts' weights are assumed to be known, but attribute weights are calculated. Little research has considered the situation that attribute weights and experts' weights are both unknown.

In order to make the calculation of qualitative factors more objective, this paper proposes an improved MAGDM method which can overcome the problem that commonly exists in previous studies (i.e., the subjective assignment of weights for attributes or experts in advance). Our method can effectively reduce the uncertainty caused by subjective weights for attributes or experts in the decision-making process and makes the calculation of qualitative factors more precise.

In sum, we solve the location problem of public transportation hubs in the following way. First, we obtain the values of qualitative factors at each alternative hub through our improved MAGDM method. Second, the quantitative factors, such as land cost and transfer distance, are considered in the model. Third, a stochastic programming is built to model the public transportation hub location problem where the passenger flow is a stochastic variable. Finally, we use the stochastic programming theory to solve the model and get the optimal location result.

\section{The Stochastic Location Model}

This section discusses the combination of quantitative and qualitative factors and establishes a public transportation hub location model under the condition that passenger flow is a stochastic variable. (Passenger flow denotes the number of passengers from one point to another. For instance, the passenger flow between points $i$ and $j$ is the number of passengers who choose the route $i$ to $j$.)

Suppose there are $n$ passenger generation points, where the coordinate of point $i$ is $\left(x_{i}, y_{i}\right)$ and $m$ alternative places for public transportation hubs, where the coordinate of alternative hub $j$ is $\left(x_{j}, y_{j}\right) . H_{j}$ denotes the maximum service capacity at alternative hub $j . C_{i j}$ denotes the transportation cost of passengers from passenger generation point $i$ to the alternative transportation hub $j . x_{i j}$ is the passenger flow from passenger generation point $i$ to the alternative transportation hub $j . d_{i j}$ is the generalized distance from passenger generation point $i$ to the alternative transportation hub $j . f_{j}$ is the fixed cost for building an alternative transportation hub $j$, including setup cost and land cost. $\delta_{i}$ denotes the number of passengers generated at point $i . Z_{j}$ denotes the evaluation value of alternative hub $j$, which reflects the influence of qualitative factors and is determined by a proposed MAGDM approach, as discussed in the next section:

$$
I_{j}= \begin{cases}1, & \text { if the alternative hub } j \text { is selected } \\ 0, & \text { otherwise. }\end{cases}
$$

We construct the mathematical model for the problem as follows:

$$
\begin{array}{cl}
\min & f_{1}(x)=\sum_{i=1}^{n} \sum_{j=1}^{m} C_{i j} x_{i j} d_{i j}+\sum_{j=1}^{m} f_{j} I_{j}, \\
\max \quad f_{2}(x)=\sum_{j=1}^{m} I_{j} Z_{j}, \\
\text { Subject to: } \quad d_{i j}=\left|x_{i}-x_{j}\right|+\left|y_{i}-y_{j}\right|, \\
& \sum_{j=1}^{m} x_{i j} \geq \delta_{i}, \quad i=1,2, \ldots, n, \\
& \sum_{i=1}^{n} x_{i j} \leq H_{j} I_{j}, \quad j=1,2,3, \ldots, m, \\
& x_{i j} \geq 0, \\
& i=1,2,3, \ldots, n, j=1,2,3, \ldots, m, \\
& I_{j}=1 \text { or } 0, \quad j=1,2,3, \ldots, m .
\end{array}
$$

Objective function (2) is to minimize the total costs. Function (3) is to maximize the total benefits of building hubs. Constraint (5) ensures that the designed passenger flow between $i$ and $j$ should be greater than or equal to the real passenger flow; namely, even in rush hour when passenger flow is greater on some routes, passengers can still choose another hub that is not necessarily the nearest. And constraint (6) limits the capacity of each alternative transportation hub. Because passenger flow is generalized from $i$ and transfers to $j$, and $j$ is the alternative, constraints (5) and (6) are the key differences between distribution center location problems and classic facility location problems.

Traditional models assume that the number of passengers for each passenger generation point is given; however, passenger flow is usually unpredictable. Ignoring this uncertainty, transportation planning and construction would involve significant risk. Therefore, in this study, we consider that passenger flow is unknown, which means that $\delta=$ $\left\{\delta_{1}, \delta_{2}, \ldots, \delta_{n}\right\}$ is a stochastic vector in the model. As a result, our model becomes a stochastic programming problem.

The procedure to solve this model is as follows. First, we transform the above stochastic programming model into a chance-constrained programming model $[23,58,59]$.

Theorem 1. Let $x$ be a decision vector, $\varepsilon$ a stochastic vector, $f(x, \varepsilon)$ the objective function, and $g_{j}(x, \varepsilon)(j=1,2, \ldots, p)$ the stochastic constraint function; the chance constraint form will be as follows:

$$
\operatorname{Pr}\{g(x, \varepsilon) \leq 0\} \geq \alpha,
$$

where $\alpha$ is the confidence level.

Suppose the stochastic vector $\varepsilon=\left\{\varepsilon_{1}, \varepsilon_{2}, \ldots, \varepsilon_{n}\right\}$ degenerates to a stochastic variable $\varepsilon$, and $\varepsilon$ 's distribution function is $\Phi$. If the form of function $g(x, \varepsilon)$ is $g(x, \varepsilon)=h(x)-\varepsilon$, 
$\operatorname{Pr}\{g(x, \varepsilon) \leq 0\} \geq \alpha$ is true if and only if $h(x) \leq K_{\alpha}$, where $K_{\alpha}=\sup \left\{K \mid K=\Phi^{-1}(1-\alpha)\right\}[23,60]$.

Proof. According to the assumptions, we can rewrite $\operatorname{Pr}\{g(x, \varepsilon) \leq 0\} \geq \alpha$ as follows:

$$
\operatorname{Pr}\{h(x) \leq \varepsilon\} \geq \alpha
$$

Obviously, for each given confidence level $\alpha(0 \leq \alpha \leq 1)$, there must exist a number $K_{\alpha}$ to meet the following equation:

$$
\operatorname{Pr}\left\{K_{\alpha} \leq \varepsilon\right\}=\alpha
$$

If a smaller number to replace $K_{\alpha}$ is used, the probability $\operatorname{Pr}\left\{K_{\alpha} \leq \varepsilon\right\}$ at the left will become higher. Therefore, $\operatorname{Pr}\{h(x) \leq \varepsilon\} \geq \alpha$ is true if and only if $h(x) \leq K_{\alpha}$. Notice that the equation $\operatorname{Pr}\left\{K_{\alpha} \leq \varepsilon\right\}=1-\Phi\left(K_{\alpha}\right)$ is always true. So we get $K_{\alpha}=\Phi^{-1}(1-\alpha)$, where $\Phi^{-1}$ is the inverse function of $\Phi$. Sometimes, the function $\Phi^{-1}$ may have multiple solutions. In this case, we will choose the largest one:

$$
K_{\alpha}=\sup \left\{K \mid K=\Phi^{-1}(1-\alpha)\right\} .
$$

Thus, we can get the equivalence of (10), which is as follows:

$$
h(x) \leq K_{\alpha} .
$$

We use Theorem 1 as the basis for solving the model. In constraint (5) of model (2), if $\delta_{i}$ is a stochastic vector, constraint condition $\sum_{j=1}^{m} x_{i j} \geq \delta_{i}$ is not meaningful. Therefore, if the probability of the constraint conditions being true is not smaller than the confidence level $\beta$, the stochastic programming model can be transformed into a chanceconstrained model. The constraint condition $\sum_{j=1}^{m} x_{i j} \geq \delta_{i}$ is converted to the following chance constraint:

$$
\operatorname{Pr}\left\{\sum_{j=1}^{m} x_{i j} \geq \delta_{i}, i=1,2, \ldots, n\right\} \geq \beta .
$$

Suppose $\delta_{i}$ follows normal distribution, and its probability distribution function is $\phi_{i}$; for Constraint (5), according to Theorem 1, for a given confidence level $\beta$, there is $\operatorname{Pr}\left\{g_{i}(x, \delta) \geq 0, j=1,2, \ldots, p\right\} \geq \beta$. Let $g(x, \delta)=h(x)-\delta$, $g(x, \delta) \leq 0$, and the chance constraint can be rewritten as follows:

$$
\operatorname{Pr}\{h(x) \geq \delta\} \geq \beta,
$$

where $h(x)$ is the linear or nonlinear function of decision variable $x, \delta$ is the stochastic variable, and probability distribution function is $\phi(\beta)$. According to (11), for each given confidence level $\beta(0 \leq \beta \leq 1)$, there must exist a number $K_{\beta}$ to satisfy the following equation:

$$
\operatorname{Pr}\left\{K_{\beta} \geq \delta\right\}=\beta \text {. }
$$

If using a larger number to replace $K_{\beta}$, the probability at the left will become higher. Therefore, $\operatorname{Pr}\{h(x) \geq \delta\} \geq$ $\beta$ becomes true if and only if $h(x) \geq K_{\beta}$. Notice that the equation $\operatorname{Pr}\left\{K_{\beta} \geq \delta\right\}=\phi(\beta)$ is always true. Thus, we get $K_{\beta}=\phi^{-1}(\beta)$, where $\phi^{-1}$ is the inverse function of $\phi$. According to (12), we will choose the largest one:

$$
K_{\beta}=\sup \left\{K \mid K=\phi^{-1}(\beta)\right\} .
$$

Thus, we can get the equivalence of (15), which is as follows:

$$
h(x) \geq K_{\beta} .
$$

Because $\operatorname{Pr}\left\{K_{\beta} \geq \delta\right\}=\beta$, then $K_{\beta}=\phi^{-1}(\beta)$. When $\sum_{j=1}^{m} x_{i j} \geq K_{\beta}, i=1,2, \ldots, n$, then $\operatorname{Pr}\left\{\sum_{j=1}^{m} x_{i j} \geq \delta_{i}, i=\right.$ $1,2, \ldots, n\} \geq \beta$. Therefore, constraint (5) $\sum_{j=1}^{m} x_{i j} \leq \delta_{i}$, $i=1,2, \ldots, n$, can be converted to

$$
\sum_{j=1}^{m} x_{i j} \geq \phi_{i}^{-1}\left(\beta_{i}\right), \quad j=1,2, \ldots, n .
$$

Thus, the original model can be transformed to

$$
\begin{array}{ll}
\min & f_{1}(x)=\sum_{i=1}^{n} \sum_{j=1}^{m} C_{i j} x_{i j} d_{i j}+\sum_{j=1}^{m} f_{j} I_{j}, \\
\max & f_{2}(x)=\sum_{j=1}^{m} I_{j} Z_{j}
\end{array}
$$

Subject to: $\quad d_{i j}=\left|x_{i}-x_{j}\right|+\left|y_{i}-y_{j}\right|$,

$$
\begin{aligned}
& \sum_{j=1}^{m} x_{i j} \geq \phi_{i}^{-1}\left(\beta_{i}\right), \quad i=1,2, \ldots, n, \\
& \sum_{i=1}^{n} x_{i j} \leq H_{j} I_{j}, \quad j=1,2,3, \ldots, m, \\
& x_{i j} \geq 0, \\
& \quad i=1,2,3, \ldots, n, j=1,2,3, \ldots, m, \\
& I_{j}=1 \text { or } 0, \quad j=1,2,3, \ldots, m .
\end{aligned}
$$

If we know each alternative hub $j$ 's evaluation value $Z_{j}$, the optimal location result can be obtained by solving the above model. Because we consider both qualitative and quantitative factors in our model, the decision results should be more accurate and practical. In the next section, we introduce an improved MAGDM approach that can objectively evaluate the attribute and expert weights. The proposed method can avoid the subjective weight assignment and reduce decision uncertainty.

\section{Determining Each Alternative's Evaluation Value Using an Improved MAGDM Approach}

This section introduces the proposed MAGDM method which can objectively assign weights to attributes and experts when these values are completely unknown in advance. 
4.1. MAGDM Problem. We first review the basic steps of MAGDM problem.

For convenience, let $M=\{1,2,3, \ldots, m\}, N=\{1,2,3, \ldots$, $n\}$, and $T=\{1,2,3, \ldots, t\}, i \in M, j \in N, K \in T$. Let $A=\left\{A_{1}, A_{2}, \ldots, A_{m}\right\}(m \geq 2)$ represent a set of $m$ feasible alternatives, let $U=\left\{u_{1}, u_{2}, \ldots, u_{n}\right\}$ represent a set of attributes, and let $D=\left\{d_{1}, d_{2}, \ldots, d_{t}\right\}$ be a set of DMs. $W=\left(w_{1}, w_{2}, \ldots, w_{n}\right)$ denotes the weight vector of attributes, where $w_{j} \geq 0, \sum_{j=1}^{n} w_{j}=1 . \lambda=\left(\lambda_{1}, \lambda_{2}, \ldots, \lambda_{t}\right)$ denotes the weight vector of DMs, where $\lambda_{k} \geq 0, \sum_{k=1}^{n} \lambda_{k}=1$.

For a MAGDM problem, suppose each alternative is evaluated based on $n$ attributes. Let

$$
\begin{aligned}
& X_{k}=\left(x_{i j}^{k}\right)_{m \times n}
\end{aligned}
$$

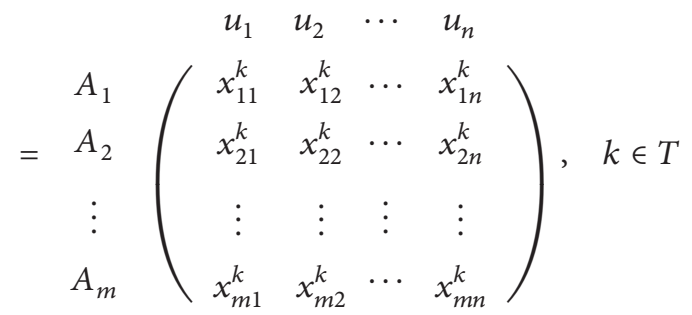

be the decision matrix of $k$ th DM. First, we normalize $X_{k}$ as $R_{k}$ :

$$
\begin{aligned}
& R_{k}=\left(r_{i j}^{k}\right)_{m \times n}=\begin{array}{c}
u_{1} \\
A_{1} \\
A_{2} \\
\vdots \\
A_{m}
\end{array}\left(\begin{array}{cccc}
r_{11}^{k} & r_{12}^{k} & \cdots & r_{1 n}^{k} \\
r_{21}^{k} & r_{22}^{k} & \cdots & r_{2 n}^{k} \\
\vdots & \vdots & \vdots & \vdots \\
r_{m 1}^{k} & r_{m 2}^{k} & \cdots & r_{m n}^{k}
\end{array}\right) \text {, } \\
& k \in T .
\end{aligned}
$$

By the given weight vector of attributes $W=\left(w_{1}, w_{2}, \ldots\right.$, $\left.w_{n}\right)^{T}$, we can establish the weighted normalized decision matrix as follows:

$$
\begin{aligned}
& Y_{k}=\left(y_{i j}^{k}\right)_{m \times n}=\left(w_{j} r_{i j}^{k}\right)_{m \times n}
\end{aligned}
$$

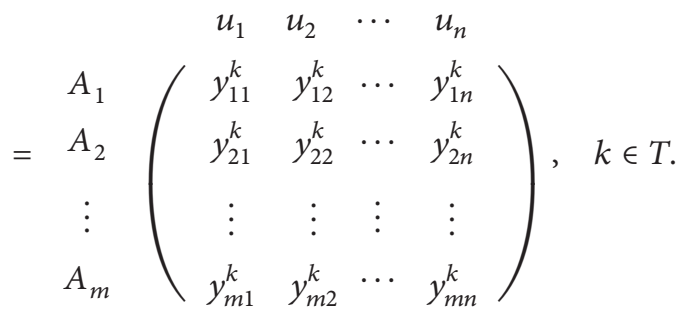

Then we can get a group decision matrix by the following equation:

$$
Y=\sum_{k=1}^{t} \lambda_{k} Y_{k}=\left(y_{i j}\right)_{m \times n}
$$

where $\lambda=\left(\lambda_{1}, \lambda_{2}, \ldots, \lambda_{t}\right)^{T}$ is the weight vector of DMs, $y_{i j}=$ $\sum_{k=1}^{t} \lambda_{k} y_{i j}^{k}$. Denote

$$
y_{i}=\sum_{j=1}^{n} y_{i j}, \quad i \in M .
$$

Using (25), we can get the evaluation value of each alternative. Most research in MAGDM problems assumes $W=\left(w_{1}, w_{2}, \ldots, w_{n}\right)$ or $\lambda=\left(\lambda_{1}, \lambda_{2}, \ldots, \lambda_{t}\right)$ is known in advance. However, the attributes of the problem are often complicated. Thus, it is difficult to directly assign weights to the attributes. And experts from different fields have different background knowledge, skills, and experience. Therefore, subjectively determining the weights of attributes and experts will increase the uncertainty of the decision-making process. Currently, little research has objectively assigned weights to both attributes and experts simultaneously. This paper proposes an improved group decision-making method that combines standard and mean deviation with improved TOPSIS. The method can objectively assign weights to the attributes and experts simultaneously. In our method, first, the standard and mean deviation maximization method is used to determine the weight of each attribute. And then an improved TOPSIS method is used to calculate the expert weights. Finally, based on the attribute weights, expert weights, and the grades which the experts give to each alternative, the final decision can be obtained. The whole decision-making process avoids subjective weighing for experts and attributes. This method reduces the uncertainty of the whole decisionmaking process and increases decision accuracy in general.

4.2. Preliminaries. Suppose that $S=\left\{s_{i} \mid i=-t, \ldots, t\right\}$ is a finite and ordered discrete term set, where $s_{i}$ represents a possible value for linguistic variables; for example, a set $S$ of nine terms can be

$$
\begin{aligned}
S & =\left\{s_{-4}=\text { extremely poor, } s_{-3}=\text { very poor, } s_{-2}\right. \\
& =\text { poor, } s_{-1}=\text { slightly poor, } s_{0}=\text { fair, } s_{1} \\
& =\text { slightly good, } s_{2}=\text { good, } s_{3}=\text { very good, } s_{4} \\
& =\text { extremely good }\}
\end{aligned}
$$

As do Herrera et al. [32-34], we have the following definitions on set $S$ :

(1) The set is ordered: $s_{i} \geq s_{j}$ if $i \geq j$.

(2) There is the negation operator: $\operatorname{neg}\left(s_{i}\right)=s_{-i}$.

(3) There is max operator: $\max \left(s_{i}, s_{j}\right)=s_{i}$, if $s_{i} \geq s_{j}$.

(4) There is min operator: $\min \left(s_{i}, s_{j}\right)=s_{i}$, if $s_{i} \leq s_{j}$.

In order to minimize the loss of linguistic information, we can extend the original language assessment scale to be continuous $\bar{S}=\left\{S_{\alpha} \mid \alpha \in[-t, t]\right\}$ [54]. If $S_{\alpha} \in \bar{S}$, we call $S_{\alpha}$ an original linguistic term. Otherwise, we call $S_{\alpha}$ a virtual linguistic term $[52,54]$. In general, the decision-maker uses the original linguistic terms to evaluate the alternatives, and the virtual linguistic terms can only appear in operation [54]. 
The operational laws for set $S$ are given as follows $[46,61]$ : Let $S_{\alpha}, S_{\beta} \in \bar{S}, \lambda_{1}, \lambda_{2} \in[0,1]$ :

(1) $S_{\alpha} \oplus S_{\beta}=S_{\alpha+\beta}$.

(2) $S_{\alpha} \oplus S_{\beta}=S_{\beta} \oplus S_{\alpha}$.

(3) $\lambda S_{\alpha}=S_{\lambda \alpha}$.

(4) $\left(S_{\alpha}\right)^{\lambda}=S_{\alpha^{\lambda}}$.

(5) $\lambda\left(S_{\alpha} \oplus S_{\beta}\right)=\lambda S_{\alpha} \oplus \lambda S_{\beta}$.

(6) $\left(\lambda_{1}+\lambda_{2}\right) S_{\alpha}=\lambda_{1} S_{\alpha} \oplus \lambda_{2} S_{\alpha}$.

Definition 2. Let $\bar{S}$ be the extended continuous linguistic term set, and $S_{i} \in \bar{S}$; then the subscript $i$ of $S_{i}$ can be obtained by the following function:

$$
\begin{gathered}
I: \bar{S} \longrightarrow[-t, t], \\
I\left(s_{i}\right)=i, \quad s_{i} \in \bar{S} .
\end{gathered}
$$

4.3. Determining the Attributes' Weights by Standard and Mean Deviation Method. Let $A=\left\{A_{1}, A_{2}, \ldots, A_{m}\right\}$ be the set of $m$ alternatives, let $U=\left\{u_{1}, u_{2}, \ldots, u_{n}\right\}$ be the set of attributes, and let $W=\left\{w_{1}, w_{2}, \ldots, w_{n}\right\}$ be the set of attribute weights, $w_{j} \in[0,1], j=1,2, \ldots, n, \sum_{j=1}^{n} w_{j}=1 . w_{j}^{(k)}$ denotes the weight given by the $k$ th DM to attribute $j . D=$ $\left\{d_{1}, d_{2}, \ldots, d_{t}\right\}$ is the set of DMs, and $\lambda=\left(\lambda_{1}, \lambda_{2}, \ldots, \lambda_{t}\right)$ is the weight vector of DMs, where $\lambda_{k} \geq 0, \sum_{k=1}^{t} \lambda_{k}=1$, $k=1,2, \ldots, t$. For each alternative $A_{i} \in A$, the DM $d_{k}$ gives his preference value $x_{i j}^{(k)}$ to attribute $u_{j} \in U$, where $x_{i j}^{(k)}$ takes the form of linguistic variable; in other words $x_{i j}^{(k)} \in \bar{S}$. Therefore, all the preference values of the alternatives consist of the decision matrix $X^{(k)}=\left(x_{i j}^{(k)}\right)_{m \times n}$.

Definition 3. Let $\left\{s_{a_{1}}, s_{a_{2}}, \ldots, s_{a_{n}}\right\}$ be a collection of linguistic arguments; a Linguistic Weighted Arithmetic Averaging (LWAA) operator is a mapping LWAA: $\overline{S^{n}} \rightarrow \bar{S}$, and defined as

$$
\begin{aligned}
& \operatorname{LWAA}_{w}\left(s_{a_{1}}, s_{a_{2}}, \ldots, s_{a_{n}}\right) \\
& \quad=w_{1} s_{a_{1}} \oplus w_{2} s_{a_{2}} \oplus \cdots \oplus w_{n} s_{a_{n}}=s_{\alpha},
\end{aligned}
$$

where $\alpha=\sum_{j=1}^{n} w_{j} I\left(s_{a_{j}}\right), w=\left(w_{1}, w_{2}, \ldots, w_{n}\right)^{T}$ is the associated weighting vector of $s_{i}, i=1,2, \ldots, n$, and $w_{j} \in$ $[0,1], i=1,2, \ldots, n, \sum_{i=1}^{n} w_{i}=1$, and $I\left(s_{a_{j}}\right)$ is the subscript of $s_{a_{j}}$. Particularly, if $w=(1 / n, 1 / n, \ldots, 1 / n)^{T}$, then the LWAA operator becomes LAA (Linguistic Arithmetic Averaging) operator [61].

Example. Assume $w=(0.2,0.3,0.4,0.1)^{T}$; then

$$
\begin{aligned}
& \operatorname{LWAA}_{w}\left(s_{4}, s_{1}, s_{-1}, s_{-2}\right) \\
& \quad=0.2 \times s_{4}+0.3 \times s_{1}+0.4 \times s_{-1}+0.1 \times s_{-2} \\
& =s_{0.2 \times 4}+s_{0.3 \times 1}+s_{0.4 \times(-1)}+s_{0.1 \times(-2)} \\
& =s_{0.2 \times 4+0.3 \times 1+0.4 \times(-1)+0.1 \times(-2)}=s_{0.5} .
\end{aligned}
$$

Definition 4. Let $s_{\alpha}, s_{\beta} \in \bar{S}$ be two linguistic variables; then

$$
d\left(s_{\alpha}, s_{\beta}\right)=\left\|s_{\alpha}-s_{\beta}\right\|=|\alpha-\beta|
$$

is the deviation between $s_{\alpha}$ and $s_{\beta}[46]$.

For expert $d_{k}$ and attribute $u_{j}$, the standard deviation between alternative $A_{i}$ and other alternatives is [62]

$$
\begin{aligned}
S_{j}^{(k)} & =\sqrt{\frac{1}{m} \sum_{i=1}^{m}\left(\left\|x_{i j}^{(k)} w_{j}^{(k)}-\frac{1}{m} \sum_{t=1}^{m} x_{i j}^{(k)} w_{j}^{(k)}\right\|\right)^{2}} \\
& =w_{j}^{(k)} \sigma_{j}^{(k)}, \quad j=1,2, \ldots, n,
\end{aligned}
$$

where

$$
\sigma_{j}^{(k)}=\sqrt{\frac{1}{m} \sum_{i=1}^{m}\left(d\left(x_{i j}^{(k)}, x_{j}^{(k)}\right)\right)^{2}} .
$$

$x_{j}^{(k)}=(1 / m) \sum_{t=1}^{m} x_{t j}^{(k)}$ represents the mean value of the attribute $u_{j}$ given by expert $d_{k} \cdot d\left(x_{i j}^{(k)}, x_{j}^{(k)}\right)$ represents the deviation of the mean value $x_{j}^{(k)}$ to the attribute value $x_{i j}^{(k)}$ of the alternative $A_{i}$ for the attribute $u_{j}$ of the expert $d_{k}$. So $S_{j}^{(k)}$ represents the standard deviation for the attribute $u_{j}$ of expert $d_{k}$

Mean deviation is

$$
\begin{aligned}
V_{j}^{(k)}=\frac{1}{m} \sum_{i=1}^{m}\left\|x_{i j}^{(k)} w_{j}^{(k)}-\frac{1}{m} \sum_{t=1}^{m} x_{t j}^{(k)} w_{j}^{(k)}\right\| & =w_{j}^{(k)} \delta_{j}^{(k)}, \\
j & =1,2, \ldots, n,
\end{aligned}
$$

where

$$
\delta_{j}^{(k)}=\frac{1}{m} \sum_{i=1}^{m} d\left(x_{i j}^{(k)}, x_{j}^{(k)}\right) .
$$

$x_{j}^{(k)}=(1 / m) \sum_{t=1}^{m} x_{t j}^{(k)}(j=1,2, \ldots, n)$ represents the mean value of attribute $u_{j}$ given by expert $d_{k}$.

$d\left(x_{i j}^{(k)}, x_{j}^{(k)}\right)$ represents the deviation of the mean value $x_{j}^{(k)}$ to the attribute value $x_{i j}^{(k)}$ of the alternative $A_{i}$ for the attribute $u_{j}$ of the expert $d_{k}$. So $V_{j}^{(k)}$ represents the mean deviation for attribute $u_{j}$ of the expert $d_{k}$.

The choice of weighed vector $w$ should make the total standard deviation and mean deviation of all evaluation indexes maximized. Therefore, the objective function can be constructed as follows:

$$
\operatorname{Max} F(w)=\sum_{j=1}^{n}\left(u S_{j}^{(k)}+v V_{j}^{(k)}\right)
$$

$$
\begin{aligned}
\text { Subject to: } & \sum_{j=1}^{n} w_{j}^{(k) 2}=1, \quad w_{j}^{(k)} \geq 0, \\
& u+v=1, \quad u \geq 0, \quad v \geq 0,
\end{aligned}
$$


where $S_{j}^{(k)}$ and $V_{j}^{(k)}$ denote the standard deviation and mean deviation for the attribute $u_{j}$ of the expert $d_{k}$, respectively, and $u$ and $v$ denote the preference of the decision-makers; $u=0$ means that the DMs only consider the mean deviation; $v=0$ denotes that the DMs only consider the standard deviation; and $u \neq 0, v \neq 0$ denote that the DMs consider the standard deviation and mean deviation simultaneously. Thus, we have the following optimization model:

$$
\operatorname{Max} \quad F(w)=\sum_{j=1}^{n} w_{j}^{(k)}\left(u \sigma_{j}^{(k)}+v \delta_{j}^{(k)}\right),
$$

Subject to: $\sum_{j=1}^{n} w_{j}^{(k) 2}=1, \quad w_{j} \geq 0, j=1,2, \ldots, n$,

$u+v=1, \quad u \geq 0, v \geq 0$.

The solution of (38) can be obtained:

$$
w_{j}^{(k)}=\frac{u \sigma_{j}^{(k)}+v \delta_{j}^{(k)}}{\sqrt{\sum_{j=1}^{n}\left(u \sigma_{j}^{(k)}+v \delta_{j}^{(k)}\right)^{2}}} .
$$

Normalizing $w_{j}^{(k)}$ we obtain

$$
\begin{aligned}
w_{j}^{*(k)}=\frac{w_{j}^{(k)}}{\sum_{j=1}^{n} w_{j}^{(k)}}=\frac{u \sigma_{j}^{(k)}+v \delta_{j}^{(k)}}{\sum_{j=1}^{n}\left(u \sigma_{j}^{(k)}+v \delta_{j}^{(k)}\right)}, & \\
& j=1,2, \ldots, n .
\end{aligned}
$$

4.4. Determining the DMs' Weights by an Improved TOPSIS Method. The traditional TOPSIS method first calculates the closeness coefficient based on the distance between the positive ideal solution denoted as PIS $A^{+}$and negative ideal solution denoted as NIS $A^{-}$and then ranks the alternatives by closeness coefficient. Here, we describe an improved TOPSIS method to calculate the expert weights $[44,45]$.

The decision matrix of $k$ th expert is

$$
\begin{aligned}
& X_{k}=\left(x_{i j}^{(k)}\right)_{m \times n}
\end{aligned}
$$

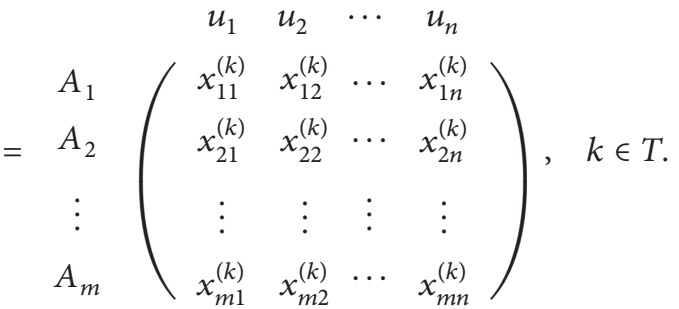

Normally, there are benefit and cost attributes in a MAGDM problem; we next use (43) to normalize the attribute value $x_{i j}$ of decision matrix $X=\left(x_{i j}\right)_{m \times n}$ to corresponding element $r_{i j}$ and then calculate the normalized matrix $[63,64]$ :

$$
\begin{aligned}
& X_{k}=\left(x_{i j}^{(k)}\right)_{m \times n}
\end{aligned}
$$

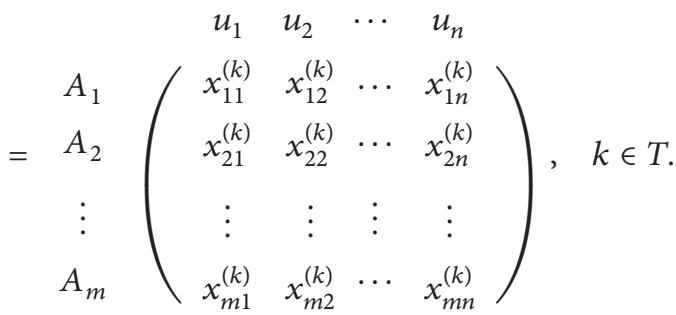

For benefit attributes $x_{i j}^{(k)}, i \in M, j \in N$, we can get

$$
r_{i j}^{(k)}=\frac{x_{i j}^{(k)}}{\sqrt{\sum_{i=1}^{m}\left(x_{i j}^{(k)}\right)^{2}}} .
$$

For cost attributes $x_{i j}^{(k)}, i \in M, j \in N$, we can get

$$
r_{i j}^{(k)}=1-\frac{x_{i j}^{(k)}}{\sqrt{\sum_{i=1}^{m}\left(x_{i j}^{(k)}\right)^{2}}} .
$$

Next, we can calculate the normalized decision matrix as follows based on the weight vectors of attribute $W=$ $\left(w_{1}, w_{2}, \ldots, w_{n}\right)$ calculated above:

$$
\begin{aligned}
& Y_{k}=\left(y_{i j}^{(k)}\right)_{m \times n}=\left(w_{j} r_{i j}^{(k)}\right)_{m \times n} \\
& \begin{array}{llll}
u_{1} & u_{2} & \cdots & u_{n}
\end{array} \\
& \begin{array}{c}
A_{1} \\
A_{2} \\
\vdots \\
A_{m}
\end{array}\left(\begin{array}{cccc}
y_{11}^{(k)} & y_{12}^{(k)} & \cdots & y_{1 n}^{(k)} \\
y_{21}^{(k)} & y_{22}^{(k)} & \cdots & y_{2 n}^{(k)} \\
\vdots & \vdots & \vdots & \vdots \\
y_{m 1}^{(k)} & y_{m 2}^{(k)} & \cdots & y_{m n}^{(k)}
\end{array}\right), \quad k \in T .
\end{aligned}
$$

At average, the best decision result should be the average matrix of the group decision matrix that is PIS [65]:

$$
\begin{aligned}
& Y^{*}=\left(y_{i j}^{*}\right)_{m \times n} \\
& \begin{array}{c}
A_{1} \\
A_{1} \\
A_{2} \\
\vdots \\
A_{m}
\end{array}\left(\begin{array}{cccc}
y_{11}^{*} & y_{12}^{*} & \cdots & y_{1 n}^{*} \\
y_{21}^{*} & y_{22}^{*} & \cdots & y_{2 n}^{*} \\
\vdots & \vdots & \vdots & \vdots \\
y_{m 1}^{*} & y_{m 2}^{*} & \cdots & y_{m n}^{*}
\end{array}\right), k \in T,
\end{aligned}
$$

where $Y^{*}=(1 / t) \sum_{k=1}^{t} Y_{k}, y_{i j}^{*}=(1 / t) \sum_{k=1}^{t} y_{i j}^{(k)}(i \in M, j \in$ $N)$. 
By the utilitarian distance, the separation $S_{k}^{+}$of each individual decision matrix $Y_{k}$ from $Y^{*}$ is given as follows:

$$
S_{k}^{+}=\left\|Y_{k}-Y^{*}\right\|=\left(\sum_{i=1}^{m} \sum_{j=1}^{n}\left(y_{i j}^{(k)}-y_{i j}^{*}\right)^{2}\right)^{1 / 2}, k \in T .
$$

Thus, the smaller the distance $S_{k}^{+}$, the better the decision $Y_{k}$ of $k$ th expert. Here, we divide the NISs into two parts LNIS $Y_{l}^{-}$and R-NIS $Y_{r}^{-}$:

$$
\begin{gathered}
Y_{l}^{-}=\begin{array}{c}
A_{1} \\
A_{2} \\
\vdots \\
A_{m}
\end{array}\left(\begin{array}{cccc}
u_{1} & u_{2} & \cdots & u_{n} \\
y_{11}^{l} & y_{12}^{l} & \cdots & y_{1 n}^{l} \\
y_{21}^{l} & y_{22}^{l} & \cdots & y_{2 n}^{l} \\
\vdots & \vdots & \vdots & \vdots \\
y_{m 1}^{l} & y_{m 2}^{l} & \cdots & y_{m n}^{l}
\end{array}\right), \\
Y_{r}^{-}=\begin{array}{c}
u_{1} \\
A_{2} \\
\vdots \\
A_{m}^{r}
\end{array}\left(\begin{array}{cccc}
y_{11}^{r} & y_{12}^{r} & \cdots & y_{1 n}^{r} \\
y_{21}^{r} & y_{22}^{r} & \cdots & y_{2 n}^{r} \\
\vdots & \vdots & \vdots & \vdots \\
y_{m 1}^{r} & y_{m 2}^{r} & \cdots & y_{m n}^{r}
\end{array}\right),
\end{gathered}
$$

where $y_{i j}^{l}=\min _{1 \leq k \leq t}\left\{y_{i j}^{(k)} \mid y_{i j}^{(k)} \leq y_{i j}^{*}\right\}, y_{i j}^{r}=\max _{1 \leq k \leq t}\left\{y_{i j}^{(k)} \mid\right.$ $\left.y_{i j}^{(k)} \geq y_{i j}^{*}\right\}$. Actually, $Y_{l}^{-}$and $Y_{r}^{-}$are the minimum and maximum matrixes of the group decision, respectively. Similarly, $S_{k}^{l-}$ and $S_{k}^{r-}$ are given as follows:

$$
\begin{aligned}
& S_{k}^{l-}=\left\|Y_{k}-Y_{l}^{-}\right\|=\left(\sum_{i=1}^{m} \sum_{j=1}^{n}\left(y_{i j}^{(k)}-y_{i j}^{l}\right)^{2}\right)^{1 / 2}, \\
& S_{k}^{r-}=\left\|Y_{k}-Y_{r}^{-}\right\|=\left(\sum_{i=1}^{m} \sum_{j=1}^{n}\left(y_{i j}^{(k)}-y_{i j}^{r}\right)^{2}\right)^{1 / 2},
\end{aligned}
$$

$$
k \in T \text {. }
$$

Obviously, the larger the value of $S_{k}^{l-}$ and $S_{k}^{r-}$, the better the decision $Y_{k}$ of $k$ th expert. The closeness coefficient of the $k$ th expert with respect to $Y^{*}$ is defined as follows:

$$
C_{k}=\frac{S_{k}^{l-}+S_{k}^{r-}}{S_{k}^{+}+S_{k}^{l-}+S_{k}^{r-}}, \quad k \in T
$$

where $S_{k}^{l-} \geq 0, S_{k}^{r-} \geq 0$, and $S_{k}^{+} \geq 0(k \in T)$. Obviously, $C_{k} \in[0,1](k \in T)$.

By the closeness coefficient, we can rank the decisionmakers' order and get the weight vectors of DMs by transforming the closeness coefficient with the following equation:

$$
\lambda_{k}=\frac{C_{k}}{\sum_{k=1}^{t} C_{k}}, \quad k \in T .
$$

Therefore,

$$
\sum_{k=1}^{t} \lambda_{k}=1, \quad \lambda_{k} \geq 0
$$

4.5. Determining the Evaluation Value. After the DMs and attributes' weights vectors are calculated based on the above analysis, the evaluation value of each alternative can be calculated by the following equation:

$$
Z_{j}=\sum_{k=1}^{t} \lambda_{k} \sum_{j=1}^{n} w_{j}^{*} I\left(x_{i j}^{(k)}\right)
$$

\section{General Steps in Decision Analysis}

Based on the above analysis, we propose a new transportation hub location method that considers both qualitative and quantitative factors. The steps of decision-making process are as follows.

Step 1. For each alternative transportation hub, expert $d_{k}(k=1,2, \ldots, t)$ gives his preference value $x_{i j}^{(k)}$ according to attribute $u_{j} \in U$, where $x_{i j}^{(k)}$ is in the form of language variables, $x_{i j}^{(k)} \in \bar{S}$. Preference values of each alternative transportation hub consist of decision matrix $X^{(k)}=\left(x_{i j}^{(k)}\right)_{m \times n}$.

Step 2. Use (41) to calculate the weight vectors of attributes $w^{*}=\left(w_{1}^{*}, w_{2}^{*}, \ldots, w_{n}^{*}\right)$ according to different $u$ and $v$.

Step 3. Use (53) to calculate the weight vectors of experts $\lambda=$ $\left(\lambda_{1}, \lambda_{2}, \ldots, \lambda_{t}\right)$.

Step 4. Use the LWAA operator to integrate the group decision-making information, and then apply (55) to calculate the evaluation value $Z_{j}$ of each alternative transportation hub.

Step 5. Use the evaluation value $Z_{j}$ of each candidate transportation hub and the given data to establish the stochastic location model (2).

Step 6. Transform model (2) into model (20).

Step 7. Solve model (20) and obtain the solution.

\section{A Numerical Study}

6.1. Evaluation Value Calculation. Usually, the public transportation hub location problem will consider many factors. Figure 1 shows several of such quantitative and qualitative factors.

Suppose there are four alternative hubs $A=$ $\left\{A_{1}, A_{2}, A_{3}, A_{4}\right\}$ and three experts $D=\left\{d_{1}, d_{2}, d_{3}\right\}$; five factors should be considered: $u_{1}$, effective connection degree, $u_{2}$, commercial potential, $u_{3}$, policy environment, $u_{4}$, 


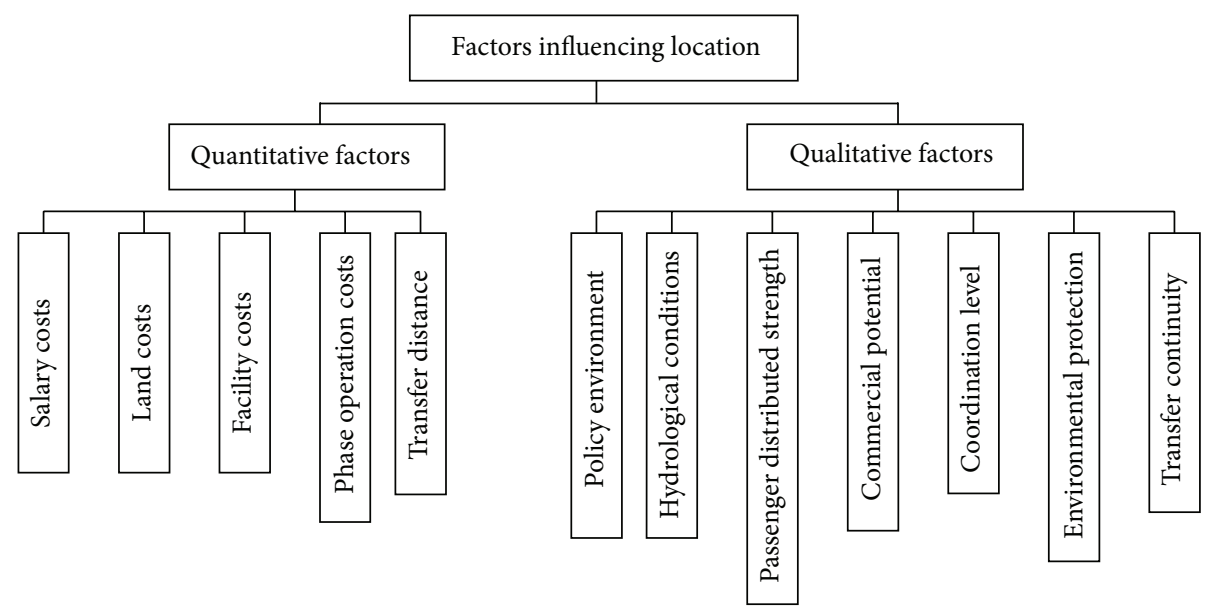

Figure 1: Factors that influence public transportation hub location.

TABLE 1: The evaluation values of four alternative hubs given by expert $d_{1}$.

\begin{tabular}{llllll}
\hline & $u_{1}$ & $u_{2}$ & $u_{3}$ & $u_{4}$ & $u_{5}$ \\
\hline$A_{1}$ & $s_{1}$ & $s_{2}$ & $s_{2}$ & $s_{3}$ & $s_{1}$ \\
$A_{2}$ & $s_{2}$ & $s_{2}$ & $s_{0}$ & $s_{2}$ & $s_{2}$ \\
$A_{3}$ & $s_{3}$ & $s_{2}$ & $s_{3}$ & $s_{1}$ & $s_{3}$ \\
$A_{4}$ & $s_{3}$ & $s_{1}$ & $s_{-1}$ & $s_{2}$ & $s_{1}$ \\
\hline
\end{tabular}

TABLE 2: The evaluation values of four alternative hubs given by expert $d_{2}$.

\begin{tabular}{llllll}
\hline & $u_{1}$ & $u_{2}$ & $u_{3}$ & $u_{4}$ & $u_{5}$ \\
\hline$A_{1}$ & $s_{0}$ & $s_{2}$ & $s_{2}$ & $s_{3}$ & $s_{2}$ \\
$A_{2}$ & $s_{2}$ & $s_{1}$ & $s_{2}$ & $s_{0}$ & $s_{2}$ \\
$A_{3}$ & $s_{2}$ & $s_{0}$ & $s_{1}$ & $s_{2}$ & $s_{3}$ \\
$A_{4}$ & $s_{0}$ & $s_{1}$ & $s_{-1}$ & $s_{0}$ & $s_{0}$ \\
\hline
\end{tabular}

environmental impact, and $u_{5}$, hydrological conditions. The language variable set is as follows:

$$
\begin{aligned}
S= & \left\{s_{-4}=\text { extremely poor, } s_{-3}=\text { very poor, } s_{-2}\right. \\
& =\text { poor, } s_{-1}=\text { slightly poor, } s_{0}=\text { fair, } s_{1} \\
& =\text { slightly good, } s_{2}=\text { good, } s_{3}=\text { very good, } s_{4} \\
& =\text { extremely good }\} .
\end{aligned}
$$

Three experts give their evaluation values in Tables 1,2 , and 3 .
TABLE 3: The evaluation values of four alternative hubs given by expert $d_{3}$.

\begin{tabular}{cccccc}
\hline & $u_{1}$ & $u_{2}$ & $u_{3}$ & $u_{4}$ & $u_{5}$ \\
\hline$A_{1}$ & $s_{1}$ & $s_{2}$ & $s_{2}$ & $s_{3}$ & $s_{2}$ \\
$A_{2}$ & $s_{0}$ & $s_{1}$ & $s_{2}$ & $s_{0}$ & $s_{3}$ \\
$A_{3}$ & $s_{3}$ & $s_{1}$ & $s_{3}$ & $s_{2}$ & $s_{-1}$ \\
$A_{4}$ & $s_{0}$ & $s_{1}$ & $s_{0}$ & $s_{0}$ & $s_{1}$ \\
\hline
\end{tabular}

Using (33) and (35), we can have

$$
\begin{aligned}
& \sigma_{j}^{(1)}=(0.6875,0.9063,2.5,0.5,0.6875), \\
& \sigma_{j}^{(2)}=(1,0.5,1.5,1.6875,1.4375), \\
& \sigma_{j}^{(3)}=(1.5,0.5625,1.1875,1.6875,2.2969), \\
& \delta_{j}^{(1)}=(0.75,0.375,1.5,0.5,0.75), \\
& \delta_{j}^{(2)}=(1,0.5,1,1.25,0.875), \\
& \delta_{j}^{(3)}=(1,0.375,0.875,1.25,1.25) .
\end{aligned}
$$

Next, using (41), the attribute weight vector related to different DMs $d_{k}(k=1,2,3)$ can be computed; here we suppose $u=v=0.5$ :

$$
\begin{aligned}
& w^{*(1)}=(0.1801,0.1512,0.3511,0.1376,0.1800) \\
& w^{*(2)}=(0.1989,0.1201,0.2213,0.2535,0.2063)
\end{aligned}
$$

$w^{*(3)}=(0.2093,0.1058,0.1848,0.2398,0.2602)$. 
Third, for the expert weights, using (43)-(45), decision matrix of expert $d_{k}$ can be normalized as follows:

$$
\begin{aligned}
& R_{1}=\left(\begin{array}{ccccc}
0.2085 & 0.5471 & 0.5345 & 0.7071 & 0.2582 \\
0.4170 & 0.5471 & 0 & 0.4714 & 0.5164 \\
0.6255 & 0.5471 & 0.8018 & 0.2357 & 0.7746 \\
0.6255 & 0.2736 & 0.7327 & 0.4714 & 0.2582
\end{array}\right), \\
& R_{2}=\left(\begin{array}{ccccc}
0 & 0.8165 & 0.6325 & 0.8320 & 0.4851 \\
0.7071 & 0.4082 & 0.6325 & 0 & 0.4851 \\
0.7071 & 0 & 0.3162 & 0.5547 & 0.7276 \\
0 & 0.4082 & 0.6838 & 0 & 0
\end{array}\right) \\
& R_{3}=\left(\begin{array}{ccccc}
0.3162 & 0.7559 & 0.4851 & 0.8320 & 0.5164 \\
0 & 0.3780 & 0.4851 & 0 & 0.7746 \\
0.9487 & 0.3780 & 0.7276 & 0.5547 & 0.7418 \\
0 & 0.3780 & 0 & 0 & 0.2582
\end{array}\right)
\end{aligned}
$$

Then, with the calculated attribute weights $w_{j}^{*}$ and (46), the normalized weighed standardization matrix can be computed as follows:

$$
\begin{aligned}
Y_{1} & =\left(y_{i j}^{(1)}\right)_{m \times n}=\left(w_{j}^{* 1} r_{i j}^{(1)}\right)_{m \times n} \\
& =\left(\begin{array}{ccccc}
0.0376 & 0.0827 & 0.1877 & 0.0973 & 0.0465 \\
0.0135 & 0.0827 & 0 & 0.0649 & 0.0930 \\
0.1127 & 0.0827 & 0.2815 & 0.0324 & 0.1394 \\
0.1127 & 0.0414 & 0.2573 & 0.0649 & 0.0465
\end{array}\right), \\
Y_{2} & =\left(\begin{array}{ccccc}
0 & 0.0981 & 0.1400 & 0.2109 & 0.1001 \\
0.1406 & 0.0490 & 0.1400 & 0 & 0.1001 \\
0.1406 & 0 & 0.0700 & 0.1406 & 0.1501 \\
0 & 0.0490 & 0.1513 & 0 & 0
\end{array}\right), \\
Y_{3} & =\left(\begin{array}{ccccc}
0.0662 & 0.0800 & 0.0896 & 0.1995 & 0.1344 \\
0 & 0.0400 & 0.0896 & 0 & 0.2016 \\
0.1986 & 0.0400 & 0.1345 & 0.1330 & 0.1930 \\
0 & 0.0400 & 0 & 0 & 0.0672
\end{array}\right)
\end{aligned}
$$

and the average matrix can be calculated by (47):

$$
Y^{*}=\left(\begin{array}{lllll}
0.0346 & 0.0869 & 0.1391 & 0.1692 & 0.0937 \\
0.0514 & 0.0572 & 0.0765 & 0.0216 & 0.1316 \\
0.1506 & 0.0409 & 0.1620 & 0.1020 & 0.1608 \\
0.0376 & 0.0435 & 0.1362 & 0.0216 & 0.0379
\end{array}\right)
$$

Using (48) we can get

$$
\begin{aligned}
& S_{1}^{+}=0.2570, \\
& S_{2}^{+}=0.1789, \\
& S_{3}^{+}=0.2022 .
\end{aligned}
$$

Using (49) we can have

$$
\begin{gathered}
Y_{l}^{-}=\left(\begin{array}{ccccc}
0 & 0.0800 & 0.0896 & 0.0973 & 0.0465 \\
0 & 0.0400 & 0 & 0 & 0.0930 \\
0.1127 & 0 & 0.0700 & 0.0324 & 0.1394 \\
0 & 0.0400 & 0 & 0 & 0
\end{array}\right), \\
Y_{r}^{-}=\left(\begin{array}{lllll}
0.0662 & 0.0981 & 0.1877 & 0.2109 & 0.1344 \\
0.1406 & 0.0827 & 0.1400 & 0.0649 & 0.2016 \\
0.1986 & 0.0827 & 0.2815 & 0.1406 & 0.1930 \\
0.1127 & 0.0490 & 0.2573 & 0.0649 & 0.0672
\end{array}\right) .
\end{gathered}
$$

Using (50), (51), and (52), we can have the following results, respectively:

$$
\begin{aligned}
& S_{1}^{l-}=0.3926, \\
& S_{2}^{l-}=0.3061, \\
& S_{3}^{l-}=0.2702, \\
& S_{1}^{r-}=0.3028, \\
& S_{2}^{r-}=0.3360, \\
& S_{3}^{r-}=0.3809, \\
& C_{1}=0.7302, \\
& C_{2}=0.7821, \\
& C_{3}=0.7630 .
\end{aligned}
$$

Therefore, using (53) the experts' weights can be obtained:

$$
\lambda=(0.3209,0.3437,0.3353) \text {. }
$$

Finally, using (55) the evaluation values of the four alternatives can be got:

$$
\begin{aligned}
& Z_{1}=0.5247 \\
& Z_{2}=0.3403 \\
& Z_{3}=0.5745 \\
& Z_{4}=0.2726
\end{aligned}
$$

6.2. Location Calculation. After calculating the evaluation values of four alternative hubs, in this section we compute the final result of the location problem. First, suppose there are five passenger generation points in the four alternative 
TABLE 4: The coordinates of the five passenger generated points.

\begin{tabular}{lcc}
\hline Serial number & $X$ coordinate & $Y$ coordinate \\
\hline 1 & 33.2 & 5.8 \\
2 & 11.9 & 6.3 \\
3 & 25.4 & 23.3 \\
4 & 15.6 & 31.6 \\
5 & 7.0 & 20.5 \\
\hline
\end{tabular}

TABLE 5: The coordinates of the four alternative hubs.

\begin{tabular}{lcc}
\hline Serial number & $X$ coordinate & $Y$ coordinate \\
\hline 1 & 12.1 & 24.4 \\
2 & 20.5 & 15.8 \\
3 & 15.4 & 11.3 \\
4 & 24.7 & 6.4 \\
\hline
\end{tabular}

TABLE 6: The generalized transportation costs (unit: Yuan).

\begin{tabular}{lccccc}
\hline$C_{i j}$ & $i=1$ & $i=2$ & $i=3$ & $i=4$ & $i=5$ \\
\hline$j=1$ & 33 & 31 & 38 & 47 & 37 \\
$j=2$ & 27 & 38 & 48 & 42 & 29 \\
$j=3$ & 25 & 42 & 44 & 32 & 36 \\
$j=4$ & 32 & 34 & 40 & 46 & 31 \\
\hline
\end{tabular}

TABLE 7: The stochastic distribution of passenger generated points.

\begin{tabular}{cccccc}
\hline & $\delta_{1}$ & $\delta_{2}$ & $\delta_{3}$ & $\delta_{4}$ & $\delta_{5}$ \\
\hline$u_{i}$ & 110 & 80 & 120 & 100 & 130 \\
$\delta_{i}$ & 20 & 20 & 40 & 15 & 10 \\
$\beta_{i}$ & 0.8 & 0.8 & 0.8 & 0.8 & 0.8 \\
\hline
\end{tabular}

hub location networks named $K_{1}, K_{2}, K_{3}, K_{4}$, and $K_{5}$. The problem is how to select the hubs in the four alternative hubs $\left(A_{1}, A_{2}, A_{3}, A_{4}\right)$ to minimize the total cost. The coordinates of the alternative hubs and the passenger generated points are shown in Tables 4 and 5.

The generalized transportation costs $C_{i j}$ of passengers from passenger generation point $i$ to the alternative transportation hub $j$ are shown in Table 6. Table 7 denotes the expected value $u$, standard deviation $\sigma$, and the confidence level $\beta_{j}$ of stochastic generated $\left\{\delta_{j}\right\}$ of the passenger generated point. Here, $H_{i}=350$ and $f_{j}=[20,19,18,22]$ (unit: ten thousand Yuan, i.e., Chinese currency).

A mathematical model can be constructed using (20). The model can be solved in two ways.

6.2.1. When Decision-Maker's Preferences Are Known. We use the linear weighted method to transform objective functions $f_{1}(x)$ and $f_{2}(x)$ into the following form:

$$
\begin{aligned}
\min f(x)= & \omega_{1}\left(\sum_{i=1}^{n} \sum_{j=1}^{m} C_{i j} x_{i j} d_{i j}+\sum_{j=1}^{m} f_{j} I_{j}\right) \\
& -\omega_{2}\left(\sum_{j=1}^{m} I_{j} Z_{j}\right) .
\end{aligned}
$$

By assigning different values to $\omega_{1}$ and $\omega_{2}$, we can obtain noninferior solutions. $f_{1}(x)$ 's dimension is "Yuan." $f_{2}(x)$ 's dimension can be considered as "satisfaction," which means the higher the evaluation value is, the more satisfaction the decision-maker has. If the decision-maker thinks that to increase $\omega_{2}$ in satisfaction is equivalent to decreasing $\omega_{1}$ Yuan in cost, the double objective problem can be converted into a single objective problem. This is because the satisfaction can be converted into cost [66].

Then, we can calculate the result as in Table 8 .

The decision-maker selects one project from Table 8 according to its own preferences. For example, if the decisionmaker chooses the 6 th solution, $A_{1}, A_{2}, A_{3}$ solution is selected.

6.2.2. When Decision-Maker's Preferences Are Unknown. When there is no information about the objective function, finding the neutral compromise solution is a good way to get the final decision [67]. Accordingly, we calculate the positive and negative ideal solution $T^{+}=(4675,1.4395)$, $T^{-}=(11190,1.1879)$ [68]. Then, we can get the compromise programming model:

$$
\begin{aligned}
& \min \max _{i=1,2} \frac{f_{i}(x)-T_{i}^{\mathrm{mid}}}{T_{i}^{-}-T_{i}^{+}}+\rho \sum_{i=1}^{2} \frac{f_{i}(x)-T_{i}^{\mathrm{mid}}}{T_{i}^{-}-T_{i}^{+}} \\
& \text {s.t. } \quad x \in S
\end{aligned}
$$

where $T_{i}^{\text {mid }}=\left(T_{i}^{-}+T_{i}^{+}\right) / 2, i=1,2$, represents the first and second objective, $S$ represents the feasible region of (68), and $\rho$ is a very small positive number.

Let $\rho=0.001$ and solve (68); we can obtain the compromise solution $(6345,1.4582)$. The corresponding decision result, $A_{1}, A_{2}, A_{3}$, is selected.

\section{Conclusions}

This paper proposes a novel approach to solving the public transportation hub location problem, by combining stochastic programming with an improved multiattribute group decision-making method and fully incorporating the relevant quantitative and qualitative factors. Firstly, we define the passenger flow as a stochastic variable and establish the stochastic location model to figure out the influence of quantitative factors. Secondly, we propose an improved MAGDM approach to figure out the influence of qualitative factors, in which standard and mean deviation method is used to determine the attributes' weights, and TOPSIS method is used to determine the DMs' weights. Thirdly, combining quantitative calculation with the qualitative MAGDM method, the optimal alternative hub is computed. Moreover, a numerical example is given to verify the developed approach and to demonstrate its practicality and effectiveness. It can be inferred that further research may focus on the application of the method in other areas and introduce more stochastic variables in the model. For instance, prospective research may treat construction and transportation costs as stochastic variables. 
TABLE 8: The noninferior solutions in different combinations of weights.

\begin{tabular}{lcccccccccccc}
\hline $\begin{array}{l}\text { Noninferior } \\
\text { solution }\end{array}$ & 1 & 2 & 3 & 4 & 5 & 6 & 7 & 8 & 9 & 10 & 11 \\
\hline$\omega_{1}$ & 0.0 & 0.1 & 0.2 & 0.3 & 0.4 & 0.5 & 0.6 & 0.7 & 0.8 & 0.9 \\
\hline$\omega_{2}$ & 1.0 & 0.9 & 0.8 & 0.7 & 0.6 & 0.5 & 0.4 & 0.3 & 0.2 & 0.1 & 0.0 \\
\hline$f_{1}(x)$ & - & 1394 & 2790 & 4185 & 5581 & 6976 & 8369 & 9766 & 9822 & 10071 & 11190 \\
\hline$f_{2}(x)$ & 1.7121 & 1.7121 & 1.7121 & 1.4395 & 1.4395 & 1.4395 & 1.4395 & 1.4395 & 1.4395 & 1.3718 & - \\
\hline $\begin{array}{l}\text { Decision } \\
\text { result }\end{array}$ & $A_{1}, A_{2}$, & $A_{1}, A_{2}$, & $A_{1}, A_{2}$, & $A_{1}, A_{2}$, & $A_{1}, A_{2}$, & $A_{1}, A_{2}$, & $A_{1}, A_{2}$, & $A_{1}, A_{2}$, & $A_{1}, A_{2}$, & $A_{1}, A_{2}$, & $A_{2}, A_{3}$, \\
$A_{3}, A_{4}$ & $A_{3}, A_{4}$ & $A_{3}$ & $A_{3}$ & $A_{3}$ & $A_{3}$ & $A_{3}$ & $A_{3}$ & $A_{3}$ & $A_{4}$ \\
\hline
\end{tabular}

\section{Conflict of Interests}

The authors declare that there is no conflict of interests regarding the publication of this paper.

\section{Acknowledgments}

This research was supported by the National Natural Science Foundation Council of China under Project 71502159, the Applied Basic Research Science Foundation of Yunnan Provincial Department of Science and Technology under Project 2015FD028, the Science Foundation of Yunnan Provincial Department of Education under Project 2015Y269, the social science major project of Yunnan Province under Project ZDZB201404, and the science and technology innovation team fund of logistics engineering in colleges and universities of Yunnan Province.

\section{References}

[1] H. Etemadnia, S. J. Goetz, P. Canning, and M. S. Tavallali, "Optimal wholesale facilities location within the fruit and vegetables supply chain with bimodal transportation options: an LP-MIP heuristic approach," European Journal of Operational Research, vol. 244, no. 2, pp. 648-661, 2015.

[2] S. Gelareh and S. Nickel, "Hub location problems in transportation networks," Transportation Research Part E: Logistics and Transportation Review, vol. 47, no. 6, pp. 1092-1111, 2011.

[3] J. F. Campbell, "Hub location for time definite transportation," Computers \& Operations Research, vol. 36, no. 12, pp. 3107-3116, 2009.

[4] C.-C. Chou, "Application of FMCDM model to selecting the hub location in the marine transportation: a case study in southeastern Asia," Mathematical and Computer Modelling, vol. 51, no. 5-6, pp. 791-801, 2010.

[5] S. Gelareh, R. Neamatian Monemi, and S. Nickel, "Multiperiod hub location problems in transportation," Transportation Research Part E: Logistics and Transportation Review, vol. 75, pp. 67-94, 2015.

[6] J. F. Campbell and M. E. O’Kelly, “Twenty-five years of hub location research," Transportation Science, vol. 46, no. 2, pp. 153169, 2012.

[7] R. Z. Farahani, M. Hekmatfar, A. B. Arabani, and E. Nikbakhsh, "Hub location problems: a review of models, classification, solution techniques, and applications," Computers \& Industrial Engineering, vol. 64, no. 4, pp. 1096-1109, 2013.
[8] J. F. Campbell, A. T. Ernst, and M. Krishnamoorthy, "Hub arc location problems: part I: introduction and results," Management Science, vol. 51, no. 10, pp. 1540-1555, 2005.

[9] R. de Andrés, M. Espinilla, and L. Martínez, "An extended hierarchical linguistic model for managing integral evaluation," International Journal of Computational Intelligence Systems, vol. 3, no. 4, pp. 486-500, 2010.

[10] M. Espinilla, R. De Andrés, F. J. Martínez, and L. Martínez, "A 360-degree performance appraisal model dealing with heterogeneous information and dependent criteria," Information Sciences, vol. 222, pp. 459-471, 2013.

[11] C. Kahraman, S. C. Onar, and B. Oztaysi, "Fuzzy multicriteria decision-making: a literature review," International Journal of Computational Intelligence Systems, vol. 8, no. 4, pp. 637-666, 2015.

[12] L. Martinez, J. Liu, and J.-B. Yang, "A fuzzy model for design evaluation based on multiple criteria analysis in engineering systems," International Journal of Uncertainty, Fuzziness and Knowlege-Based Systems, vol. 14, no. 3, pp. 317-336, 2006.

[13] I. Palomares, R. M. Rodríguez, and L. Martínez, "An attitudedriven web consensus support system for heterogeneous group decision making," Expert Systems with Applications, vol. 40, no. 1, pp. 139-149, 2013.

[14] H. Damgacioglu, D. Dinler, N. Evin Ozdemirel, and C. Iyigun, "A genetic algorithm for the uncapacitated single allocation planar hub location problem," Computers and Operations Research, vol. 62, pp. 224-236, 2015.

[15] Y. He, T. Wu, C. Zhang, and Z. Liang, "An improved MIP heuristic for the intermodal hub location problem," Omega, vol. 57, part B, pp. 203-211, 2015.

[16] J. F. Campbell, A. T. Ernst, and M. Krishnamoorthy, "Hub arc location problems: part II: formulations and optimal algorithms," Management Science, vol. 51, no. 10, pp. 1556-1571, 2005.

[17] A. G. Robinson and J. H. Bookbinder, "NAFTA supply chains: facilities location and logistics," International Transactions in Operational Research, vol. 14, pp. 179-199, 2007.

[18] S. Alumur and B. Y. Kara, "Network hub location problems: the state of the art," European Journal of Operational Research, vol. 190, no. 1, pp. 1-21, 2008.

[19] I. Contreras, J.-F. Cordeau, and G. Laporte, "Stochastic uncapacitated hub location," European Journal of Operational Research, vol. 212, no. 3, pp. 518-528, 2011.

[20] F. V. Louveaux and D. Peeters, "A dual-based procedure for stochastic facility location," Operations Research, vol. 40, no. 3, pp. 564-573, 1992.

[21] M. O. Ball and F. L. Lin, "Reliability model applied to emergency service vehicle location," Operations Research, vol. 41, no. 1, pp. 18-36, 1993. 
[22] M. Albareda-Sambola, E. Fernández, and G. Laporte, "Heuristic and lower bound for a stochastic location-routing problem," European Journal of Operational Research, vol. 179, no. 3, pp. 940-955, 2007.

[23] J. Zhou and B. Liu, "New stochastic models for capacitated location-allocation problem," Computers and Industrial Engineering, vol. 45, no. 1, pp. 111-125, 2003.

[24] S. Gelareh and D. Pisinger, "Fleet deployment, network design and hub location of liner shipping companies," Transportation Research Part E: Logistics and Transportation Review, vol. 47, no. 6, pp. 947-964, 2011.

[25] M. Wen and R. Kang, "Some optimal models for facility location-allocation problem with random fuzzy demands," Applied Soft Computing Journal, vol. 11, no. 1, pp. 1202-1207, 2011.

[26] A. F. Gabor and J. C. W. Van Ommeren, "An approximation algorithm for a facility location problem with stochastic demands and inventories," Operations Research Letters, vol. 34, no. 3, pp. 257-263, 2006.

[27] B.-H. Wang and S.-W. He, "Robust optimization model and algorithm for logistics center location and allocation under uncertain environment," Journal of Transportation Systems Engineering and Information Technology, vol. 9, no. 2, pp. 6974, 2009.

[28] L. Yang, X. Ji, Z. Gao, and K. Li, "Logistics distribution centers location problem and algorithm under fuzzy environment," Journal of Computational and Applied Mathematics, vol. 208, no. 2, pp. 303-315, 2007.

[29] L. Yang, B. F. Jones, and S.-H. Yang, "A fuzzy multi-objective programming for optimization of fire station locations through genetic algorithms," European Journal of Operational Research, vol. 181, no. 2, pp. 903-915, 2007.

[30] H. Yaman and G. Carello, "Solving the hub location problem with modular link capacities," Computers and Operations Research, vol. 32, no. 12, pp. 3227-3245, 2005.

[31] S.-P. Wan and J.-Y. Dong, "Interval-valued intuitionistic fuzzy mathematical programming method for hybrid multi-criteria group decision making with interval-valued intuitionistic fuzzy truth degrees," Information Fusion, vol. 26, pp. 49-65, 2015.

[32] F. Herrera, E. Herrera-Viedma, and L. Martínez, "A fusion approach for managing multi-granularity linguistic term sets in decision making," Fuzzy Sets and Systems, vol. 114, no. 1, pp. 4358, 2000.

[33] F. Herrera, E. Herrera-Viedma, and J. L. Verdegay, "Direct approach processes in group decision making using linguistic OWA operators," Fuzzy Sets and Systems, vol. 79, no. 2, pp. 175190, 1996.

[34] F. Herrera, E. Herrera-Viedma, and J. L. Verdegay, "A sequential selection process in group decision making with a linguistic assessment approach," Information Sciences, vol. 85, no. 4, pp. 223-239, 1995.

[35] F. Herrera and L. Martínez, "A model based on linguistic 2tuples for dealing with multigranular hierarchical linguistic contexts in multi-expert decision-making," IEEE Transactions on Systems, Man, and Cybernetics, Part B: Cybernetics, vol. 31, no. 2, pp. 227-234, 2001.

[36] N. Karacapilidis, "Integrating new information and communication technologies in a group decision support system," International Transactions in Operational Research, vol. 7, no. 6, pp. 487-507, 2000.

[37] R. Lahdelma and P. Salminen, "SMAA-2: stochastic multicriteria acceptability analysis for group decision making," Operations Research, vol. 49, no. 3, pp. 444-454, 2001.
[38] N. Fenton and W. Wang, "Risk and confidence analysis for fuzzy multicriteria decision making," Knowledge-Based Systems, vol. 19, no. 6, pp. 430-437, 2006.

[39] D. S. Hochbaum and A. Levin, "Methodologies and algorithms for group-rankings decision," Management Science, vol. 52, no. 9, pp. 1394-1408, 2006.

[40] J. R. P. French Jr., "A formal theory of social power," Psychological Review, vol. 63, no. 3, pp. 181-194, 1956.

[41] S. E. Bodily, "A delegation process for combining individual utility functions," Management Science, vol. 25, no. 10, pp. 10351041, 1979.

[42] Z. Yue, Y. Jia, and G. Ye, "An approach for multiple attribute group decision making based on intuitionistic fuzzy information," International Journal of Uncertainty, Fuzziness and Knowledge-Based Systems, vol. 17, no. 3, pp. 317-332, 2009.

[43] R. O. Parreiras, P. Y. Ekel, J. S. C. Martini, and R. M. Palhares, "A flexible consensus scheme for multicriteria group decision making under linguistic assessments," Information Sciences, vol. 180, no. 7, pp. 1075-1089, 2010.

[44] Z. Yue, "A method for group decision-making based on determining weights of decision makers using TOPSIS," Applied Mathematical Modelling, vol. 35, no. 4, pp. 1926-1936, 2011.

[45] Z. Yue, "An extended TOPSIS for determining weights of decision makers with interval numbers," Knowledge-Based Systems, vol. 24, no. 1, pp. 146-153, 2011.

[46] Z. Xu, "A method for multiple attribute decision making with incomplete weight information in linguistic setting," Knowledge-Based Systems, vol. 20, no. 8, pp. 719-725, 2007.

[47] B. G. Mirkin and P. C. Fishburn, Group Choice, Halsted Press, 1979.

[48] R. C. Van den Honert, "Decisional power in group decision making: a note on the allocation of group members' weights in the multiplicative AHP and SMART," Group Decision and Negotiation, vol. 10, no. 3, pp. 275-286, 2001.

[49] R. Ramanathan and L. S. Ganesh, "Group preference aggregation methods employed in AHP: an evaluation and an intrinsic process for deriving members' weightages," European Journal of Operational Research, vol. 79, no. 2, pp. 249-265, 1994.

[50] $\mathrm{Z}$. Xu, "A method based on linguistic aggregation operators for group decision making with linguistic preference relations," Information Sciences, vol. 166, no. 1-4, pp. 19-30, 2004.

[51] Z. Xu, "Uncertain linguistic aggregation operators based approach to multiple attribute group decision making under uncertain linguistic environment," Information Sciences, vol. 168, no. 1-4, pp. 171-184, 2004.

[52] Z. Xu, "Deviation measures of linguistic preference relations in group decision making," Omega, vol. 33, no. 3, pp. 249-254, 2005.

[53] Z. Xu, "An approach based on the uncertain LOWG and induced uncertain LOWG operators to group decision making with uncertain multiplicative linguistic preference relations," Decision Support Systems, vol. 41, no. 2, pp. 488-499, 2006.

[54] Z. Xu, "Induced uncertain linguistic OWA operators applied to group decision making," Information Fusion, vol. 7, no. 2, pp. 231-238, 2006.

[55] J. M. Merigó, M. Casanovas, and L. Martínez, "Linguistic aggregation operators for linguistic decision making based on the dempster-shafer theory of evidence," International Journal of Uncertainty, Fuzziness and Knowlege-Based Systems, vol. 18, no. 3, pp. 287-304, 2010. 
[56] F. Meng and J. Tang, "Extended 2-tuple linguistic hybrid aggregation operators and their application to multi-attribute group decision making," International Journal of Computational Intelligence Systems, vol. 7, no. 4, pp. 771-784, 2014.

[57] Y. Xu, J. M. Merigó, and H. Wang, "Linguistic power aggregation operators and their application to multiple attribute group decision making," Applied Mathematical Modelling, vol. 36, no. 11, pp. 5427-5444, 2012.

[58] B. Liu, Uncertain Programming, Wiley, New York, NY, USA, 1999.

[59] B. Liu and K. Iwamura, "Fuzzy programming with fuzzy decisions and fuzzy simulation-based genetic algorithm," Fuzzy Sets and Systems, vol. 122, no. 2, pp. 253-262, 2001.

[60] B. Liu, R. Zhao, and G. Wang, Uncertain Programming with Applications, Tsinghua University Press, Beijing, China, 2008.

[61] Z. Wu and Y. Chen, "The maximizing deviation method for group multiple attribute decision making under linguistic environment," Fuzzy Sets and Systems, vol. 158, no. 14, pp. 16081617, 2007.

[62] Y.-J. Xu and Q.-L. Da, "Standard and mean deviation methods for linguistic group decision making and their applications," Expert Systems with Applications, vol. 37, no. 8, pp. 5905-5912, 2010.

[63] I. Chamodrakas, I. Leftheriotis, and D. Martakos, "In-depth analysis and simulation study of an innovative fuzzy approach for ranking alternatives in multiple attribute decision making problems based on TOPSIS," Applied Soft Computing Journal, vol. 11, no. 1, pp. 900-907, 2011.

[64] G. R. Jahanshahloo, F. H. Lotfi, and M. Izadikhah, "An algorithmic method to extend TOPSIS for decision-making problems with interval data," Applied Mathematics and Computation, vol. 175, no. 2, pp. 1375-1384, 2006.

[65] M. K. Sayadi, M. Heydari, and K. Shahanaghi, "Extension of VIKOR method for decision making problem with interval numbers," Applied Mathematical Modelling, vol. 33, no. 5, pp. 2257-2262, 2009.

[66] B. Jurgen, D. Kalyanmoy, and M. Kaisa, Multiobjective Optimization: Interactive and Evolutionary Approaches, Springer, Berlin, Germany, 2008.

[67] A. P. Wierzbicki, Reference Point Approaches, Kluwer Academic Publishers, Dordrecht, The Netherlands, 1999.

[68] P. Giovanni, Y. Lurdes, and I. Tani, Decision Theory: Principles and Approaches, Wiley, New York, NY, USA, 2009. 


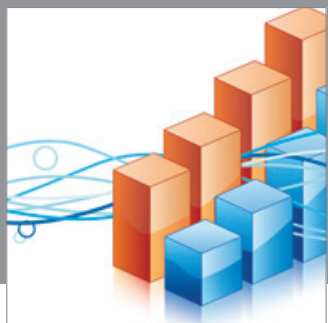

Advances in

Operations Research

mansans

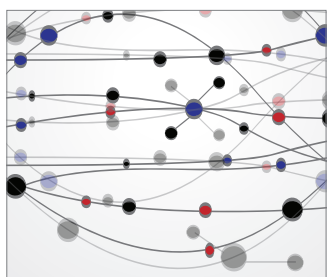

The Scientific World Journal
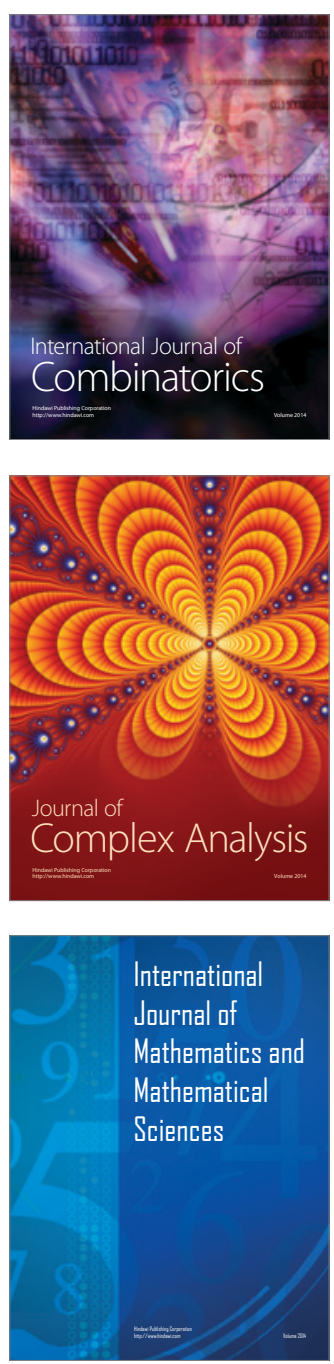
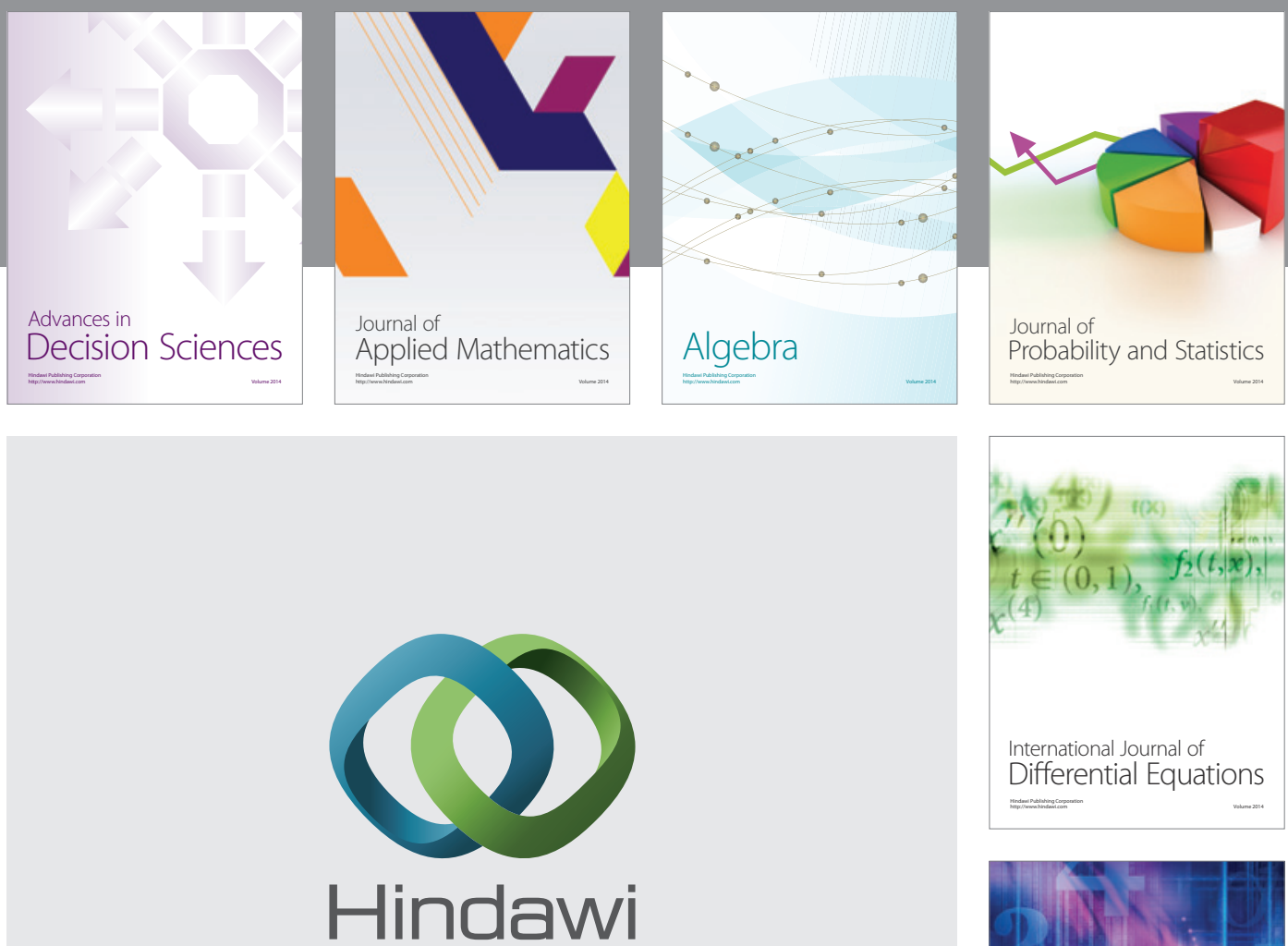

Submit your manuscripts at http://www.hindawi.com
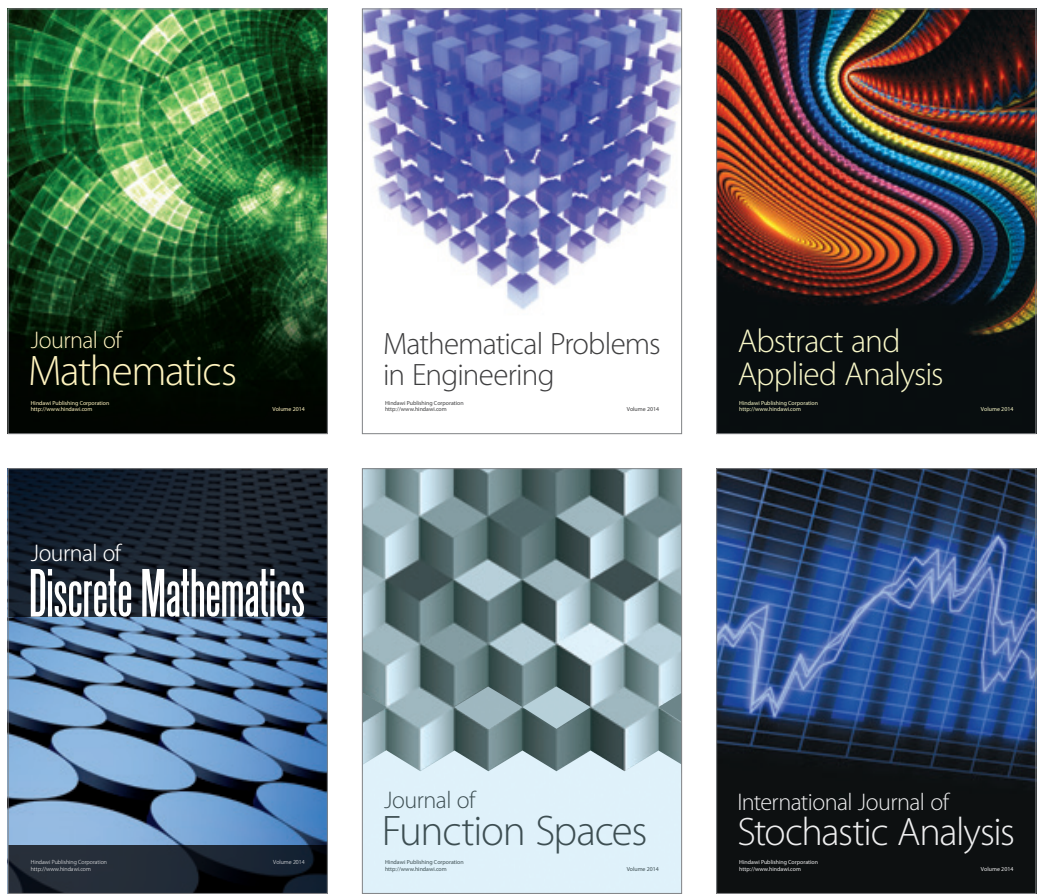

Journal of

Function Spaces

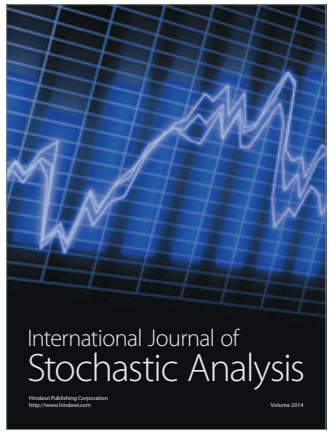

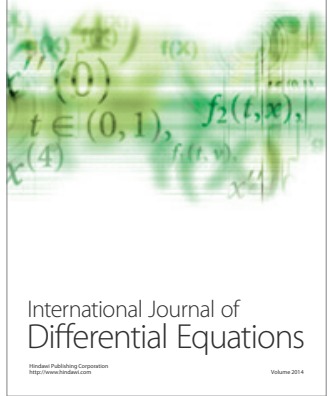
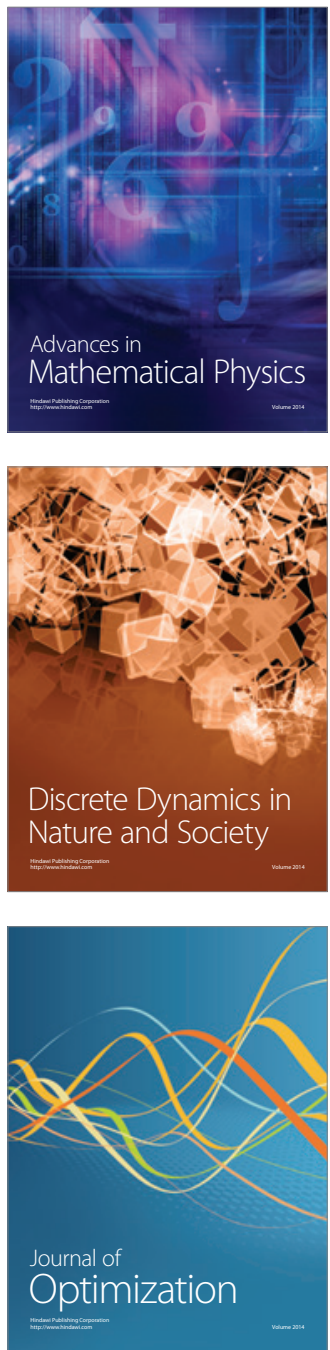